\title{
Resposta fisiológica de sementes de Erythrina velutina Willd. ao envelhecimento acelerado
}

\author{
Physiological response of Erythrina velutina Willd. \\ seeds to accelerated aging
}

\author{
Roberta Sales Guedes ${ }^{1 *}$; Edna Ursulino Alves ${ }^{2}$; Edilma Pereira Gonçalves ${ }^{3}$; \\ Jeandson Silva Viana ${ }^{4}$; Riselane de Lucena Alcântara Bruno; \\ Pedro Nóbrega Quintas Colares ${ }^{5}$
}

\section{Resumo}

A avaliação do vigor de sementes tem sido fundamental dentro de programas de controle de qualidade. O teste de envelhecimento acelerado (EA) é uma das opções disponíveis, mas não há informações suficientes sobre sua eficiência para sementes florestais, como as de Erythrina velutina. Para tanto, foi conduzido um experimento em laboratório na Universidade Federal da Paraíba, com o objetivo de estudar procedimentos para condução do teste de EA para avaliar o potencial fisiológico das sementes dessa espécie. $\mathrm{O}$ envelhecimento acelerado foi conduzido a 41 e $45^{\circ} \mathrm{C}$ durante $24,48,72$ e 96 horas, além da testemunha (sementes não envelhecidas). Realizou-se o teste de emergência das plântulas em campo, a fim de averiguar a qualidade fisiológica das sementes. As sementes foram distribuídas em camada única sobre tela, em caixas plásticas com $40 \mathrm{~mL}$ de água destilada, no interior de câmara BOD. $\mathrm{O}$ teor de água e a germinação das sementes foram determinados antes e após o EA. Os resultados revelaram que as combinações $41^{\circ} \mathrm{C} / 72$ horas e $45^{\circ} \mathrm{C} / 24$ horas são adequadas para avaliação do vigor de sementes de Erythrina velutina.

Palavras-chave: Germinação, mulungu, sementes, vigor

\begin{abstract}
Seed vigor testing is an important component of quality control programs, and accelerated aging is a possible option in this process. This study was conducted to investigate procedures to assess seed vigor by the accelerated aging test in forest seeds of Erythrina velutina. The experiment was realized at laboratory conditions at Universidade Federal da Paraíba, in Areia - PB, Brazil Northeast. The seeds were stored in plastic bags and kept at $10^{\circ} \mathrm{C}$ and $50 \%$ relative humidity. Accelerated aging was performed at $41^{\circ} \mathrm{C}$ during 24, 48, 72, and 96 hours; Accelerated aging test identified differences among seed lots of high and low physiological quality. Seeds were kept in plastic boxes with $40 \mathrm{~mL}$ of distilled water in a BOD chamber. Seeds were tested for germination and moisture content before and after aging. The results revealed that the combinations $41^{\circ} \mathrm{C} / 72$ hours and $45^{\circ} \mathrm{C} / 24$ hours are appropriate for evaluation of the vigor of Erythrina velutina seeds
\end{abstract}

Key words: Germination, mulungu, seeds, vigor

\footnotetext{
Bióloga, Mestranda do Curso de Pós-graduação em Agronomia, Depto. de Fitotecnia, CCA-UFPB; Areia-PB, Brasil; e-mail: roberta biologa09@yahoo.com.br.

2 Prof. Adjuntos do Depto. de Fitotecnia, CCA/UFPB; e-mail: ednaursulino@cca.ufpb.br.

3 Prof. Adjunta UFRPE - UAG, Garanhuns - PE; e-mail: edilmapg@hotmail.com.

4 Prof. Adjunto UFRPE - UAST, Serra Talhada - PE; e-mail: jeandsonsv@hotmail.com.

5 Aluno de Graduação em Agronomia Depto. de Fitotecnia, CCA-UFPB; Areia-PB.

Autor para correspondência
} 


\section{Introdução}

Rotineiramente a qualidade fisiológica das sementes é analisada pelo teste de germinação, contudo esse teste é realizado em condições favoráveis de umidade, temperatura e substrato, permitindo que o lote expresse sua máxima germinação. Entretanto, esse teste pode ter pouca eficiência para estimar o desempenho no campo, onde as condições nem sempre são favoráveis. Desta forma, os resultados de emergência das plântulas em campo podem ser consideravelmente inferiores aos obtidos no teste de germinação em laboratório.

Os testes de vigor possibilitam identificar os lotes com maior ou menor probabilidade de apresentar melhor comportamento no campo ou durante o armazenamento. Portanto, o objetivo essencial dos testes de vigor é verificar diferenças importantes no potencial fisiológico de lotes de sementes, especialmente daqueles que apresentam poder germinativo elevado e semelhante (MARCOS FILHO, 1999a).

Um dos testes mais utilizados para a avaliação do vigor é o envelhecimento acelerado (MARCOS FILHO, 1999b), sendo enfatizado por sua capacidade de proporcionar informações com alto grau de consistência (MARCOS FILHO, 1999a). O envelhecimento acelerado é um teste de vigor baseado na simulação de fatores ambientais adversos, temperatura e umidade relativa elevadas, que são relacionadas como causadoras da deterioração das sementes. Os processos de deterioração ocorridos neste teste são semelhantes aos que ocorrem no envelhecimento natural das sementes, porém, a uma velocidade acelerada (DELOUCHE; BASKIN, 1973; MARCOS FILHO, 1999b). Sob essas condições, sementes de baixa qualidade deterioram-se mais rapidamente do que sementes mais vigorosas, estabelecendo diferenças no potencial fisiológico das amostras avaliadas.

Lotes de sementes de alto vigor devem manter sua viabilidade quando submetidos a tais condições, enquanto que os de baixo vigor terão sua viabilidade reduzida (ASSOCIATION OF OFFICIAL SEED ANALYSTS - AOSA, 1983). Este teste originalmente foi desenvolvido com a finalidade de estimar a longevidade de sementes armazenadas, hoje tem sido amplamente estudado com vistas à sua padronização (RODO; PANOBIANCO; MARCOS FILHO, 2000), tendo em vista que os processos de deterioração ocorridos neste teste são semelhantes aos que ocorrem no envelhecimento natural das sementes, porém, a uma velocidade acelerada (MARCOS FILHO, 1999b).

Ainteraçãoentretemperaturaetempodeexposição das sementes às condições de envelhecimento são fatores importantes para a eficiência do teste, e para muitas espécies essa interação ainda não foi estabelecida. $\mathrm{O}$ teste de envelhecimento acelerado pode ser conduzido com temperaturas entre 41 e $45^{\circ} \mathrm{C}$, sendo que recentemente a maioria dos trabalhos indica o uso de $41^{\circ} \mathrm{C}$ (MARCOS FILHO, 1999b). No entanto, Menezes e Nascimento (1988) constataram que a interação $37^{\circ} \mathrm{C} / 72 \mathrm{~h}$ foram os mais eficientes para avaliação do vigor de sementes de Pisum sativum. Para Nepeta cataria e Oreganum vulgare, $42^{\circ} \mathrm{C} / 48 \mathrm{~h}$ (BAGGIO et al., 2003), para soja, $42^{\circ} \mathrm{C} / 48 \mathrm{~h}$ (DUTRA; VIEIRA, 2004). Para sementes de Cedrela fissilis $50^{\circ} \mathrm{C} / 24 \mathrm{~h}$ (BORGES; CASTRO; BORGES, 1991) e para sementes de Anadenanthera colubrina $40^{\circ} \mathrm{C} / 24 \mathrm{~h}$ (GARCIA; NOGUEIRA; ABREU, 2004). Em sementes de Piptadenia communis, observa-se redução significativa da viabilidade das sementes, quando submetidas ao envelhecimento acelerado à temperatura $40^{\circ} \mathrm{C}$ (BORGES; CASTRO; BORGES, 1992).

Em virtude da utilização das espécies de modo extrativista, é necessário estudar melhor as espécies nativas quanto à propagação, de forma a dar subsídios aos plantios comerciais e a revegetação de áreas de extrativismo e preservação ambiental. O mulungu (Erythrina velutina) por apresentar considerável importância econômica (KUKIHARA; IMAÑA-ENCINAS; PAULA, 2005; LIRA et al., 2004) e na medicina popular (LORENZI, 1992) merece atenção especial quanto à avaliação do seu 
potencial fisiológico, para tanto, estudos dirigidos à determinação do vigor devem ser realizados por não existir informações sobre a espécie.

Várias pesquisas têm sido realizadas utilizandose o envelhecimento artificial com o intuito de avaliar as alterações que ocorrem em sementes e plântulas. No entanto, há dificuldades na sua aplicação devido à falta de padronização da temperatura para condução do teste. Face à relevância de tais estudos e a escassez de informações neste aspecto, com espécies florestais, este trabalho teve como objetivo determinar a melhor temperatura e tempo de exposição para a condução de teste de envelhecimento acelerado, que possibilitasse avaliar o vigor das sementes de Erythrina velutina.

\section{Material e Métodos}

A pesquisa foi conduzida no Laboratório de Análise de Sementes do Centro de Ciências Agrárias da Universidade Federal da Paraíba, em Areia-PB, entre outubro e novembro de 2007. Foi utilizado um lote de sementes de Erythrina velutina procedentes de oito matrizes, no município de AreiaPB. As sementes foram submetidas as seguintes determinações e testes:

Teor de água - realizado conforme Brasil (1992), utilizando quatro subamostras de 10 sementes colocadas em cápsulas de alumínio em estufa a $105^{\circ} \mathrm{C} \pm 3^{\circ} \mathrm{C}$, por 24 horas e os resultados expressos em porcentagem.

Teste de germinação - na avaliação da germinação foram utilizadas 100 sementes, as quais foram divididas em quatro repetições de 25 . As sementes foram previamente escarificadas na região oposta a micrópila, com lixa d'água $n^{\circ} 80$ e colocadas para germinar no substrato de papel germitest, distribuídas na forma de rolo, umedecido com água destilada equivalente a 3 vezes o peso do papel seco e mantidas em câmaras de germinação (B.O.D.) sob temperatura de $25^{\circ} \mathrm{C}$. Ao final do teste (15 dias) computou-se o número de plântulas normais segundo o critério proposto por Brasil (1992).

\section{Emergência de plântulas em campo - na} avaliação da emergência foram utilizadas 100 sementes escarificadas, as quais foram divididas em quatro repetições de 25 e semeadas a $2,0 \mathrm{~cm}$ de profundidade em sulcos de 1,0 $\mathrm{m}$ de comprimento e distanciadas $10 \mathrm{~cm}$ entre si. Realizou-se contagens diárias do $4^{\circ}$ até $21^{\circ}$ dia após a semeadura, sendo consideradas emergidas as plântulas que apresentavam os cotilédones acima do solo. Determinou-se o percentual de emergência das plântulas e os resultados foram expressos em porcentagem (NAKAGAWA, 1999).

Envelhecimento acelerado - ensaios de aprimoramento da metodologia do envelhecimento acelerado foram realizados, testando-se as temperaturas de $41^{\circ} \mathrm{C}$ e $45^{\circ} \mathrm{C}$, combinados com diferentes tempos de exposição das sementes ao estresse e comparando-se os resultados à emergência de plântulas em campo, para se obter as recomendações adequadas para validar o teste. Para a condução do teste utilizou-se o procedimento proposto pela AOSA (1983) e descrito por Marcos Filho (1999b). Foram distribuídas uniformemente 100 sementes escarificadas sobre uma tela de alumínio, fixada em caixa plástica tipo "gerbox", contendo $40 \mathrm{~mL}$ de água. As caixas, com as sementes, foram fechadas e mantidas em germinadores com temperaturas controladas a $41^{\circ} \mathrm{C}$ e $45^{\circ} \mathrm{C}(100 \%$ UR $)$ por 24, 48 e 72 e 96 horas. Foi testado o período zero que corresponde a testemunha. Ao término de cada período, as sementes foram submetidas ao teste de germinação e a porcentagem de plântulas normais foi computada no quarto dia após a semeadura. Determinou-se também, o teor de água das sementes antes e após os diferentes períodos de envelhecimento, visando avaliar a uniformidade das condições do teste.

Teste de condutividade elétrica - foram empregadas quatro repetições de 25 sementes escarificadas, submetidas a cada temperatura (41 e 
$45^{\circ} \mathrm{C}$ ) e período de exposição do envelhecimento $(0,24,48,72$ e $96 \mathrm{~h})$, as quais foram pesadas e embebidas em $75 \mathrm{~mL}$ de água destilada dentro de Becker por 24 horas sob $25^{\circ} \mathrm{C}$ (VIEIRA; KRZYZANOWSKI, 1999). Passado esseperíodo de embebição foram realizadas, com condutivímetro, as leituras cujos valores determinados foram divididos pelas massas relativas às 25 sementes e expressos em $\mu$ mho. $\mathrm{cm}^{-1}$. $\mathrm{g}^{-1}$.

Delineamento Experimental e Análise estatística - a análise estatística dos dados foi realizada, segundo o delineamento experimental inteiramente ao acaso, com os tratamentos dispostos em esquema fatorial $2 \times 5$ sendo duas temperaturas $\left(41^{\circ} \mathrm{C}\right.$ e $\left.45^{\circ} \mathrm{C}\right)$ e cinco períodos de envelhecimento $(0,24$, 48, 72 e 96h), em quatro repetições. Os dados, não transformados, foram submetidos à análise de variância e de regressão polinomial.

\section{Resultados e Discussão}

O teste de emergência de plântulas em campo indica que as sementes de Erythrina velutina apresentavam alta qualidade fisiológica, com um percentual de emergência de $84 \%$. Este teste é considerado o melhor indicativo para inferir sobre o vigor de sementes, pois na sua execução devem ser utilizadas condições que simulem aquelas que as sementes estarão sujeitas por ocasião da semeadura em campo. Durante o período de condução do teste, o ambiente apresentou temperatura de $23^{\circ} \mathrm{C}$ e umidade relativa de $87 \%$.

Os resultados relativos ao teor de água inicial das sementes e os teores atingidos após a realização dos tratamentos de envelhecimento acelerado estão apresentados na Figura 1. No início do teste o teor de água das sementes variou de 7,55 a 8,70\% sugerindo que esse parâmetro se encontrava na faixa indicada para realização do teste. Diferenças de 1 a $2 \%$ no teor de água entre amostras não são comprometedoras. Entretanto, diferenças acentuadas podem provocar alterações na velocidade de umedecimento das sementes durante o tratamento de envelhecimento e determinar diferenças na intensidade de deterioração (MARCOS FILHO, 1999b).

Após 24 horas de envelhecimento verificou-se em geral que as sementes absorveram água, atingindo às 96 horas valores superiores a $20 \%$ em ambas as temperaturas $\left(41 \mathrm{e} 45^{\circ} \mathrm{C}\right)$. De acordo com Carvalho e Nakagawa (2000), incrementos nos teores de água favorecem o aumento da temperatura na semente, em decorrência dos processos respiratórios e da maior atividade de microorganismos. $\mathrm{O}$ aumento de tempo de exposição ao envelhecimento acelerado pode ter proporcionado maior incremento no teor de água nas sementes condicionadas, que, aliado à temperatura elevada $\left(45^{\circ} \mathrm{C}\right)$ imposta pelo teste de envelhecimento, resultou em um processo de deterioração mais acelerado dessas sementes em relação às sementes não envelhecidas precocemente ou envelhecidas com temperaturas menores $\left(41^{\circ} \mathrm{C}\right)$.

Em todas as avaliações, no final do teste, verificou-se que não houve variações acentuadas do grau de umidade da semente, sugerindo boa uniformidade na condução do envelhecimento acelerado, de acordo com Marcos Filho (1999b), segundo o qual variações entre 3 e $4 \%$ entre as amostras são toleráveis.

Os resultados da avaliação da qualidade fisiológica das sementes de Erythrina velutina são apresentados na Figura 2. Observa-se um decréscimo significativo no percentual de plântulas normais, à medida que as sementes foram envelhecidas. Quando as sementes foram submetidas à temperatura de $41^{\circ} \mathrm{C}$, no entanto, não foram observadas grandes diferenças significativas no tempo de 24 horas, em relação ao controle (0 hora), mas estes foram superiores aos demais, indicando haver uma redução drástica da qualidade fisiológica das sementes, a partir de 72 horas de envelhecimento. Resultados semelhantes foram verificados com sementes de Ocimum gratissimum L. (LIMA; ATHANÁZIO; BELLETTINI, 2006), Pimpinella asinum L. (TORRES, 2004) e Cucumis anguria L (TORRES; MARCOS FILHO, 2001). 


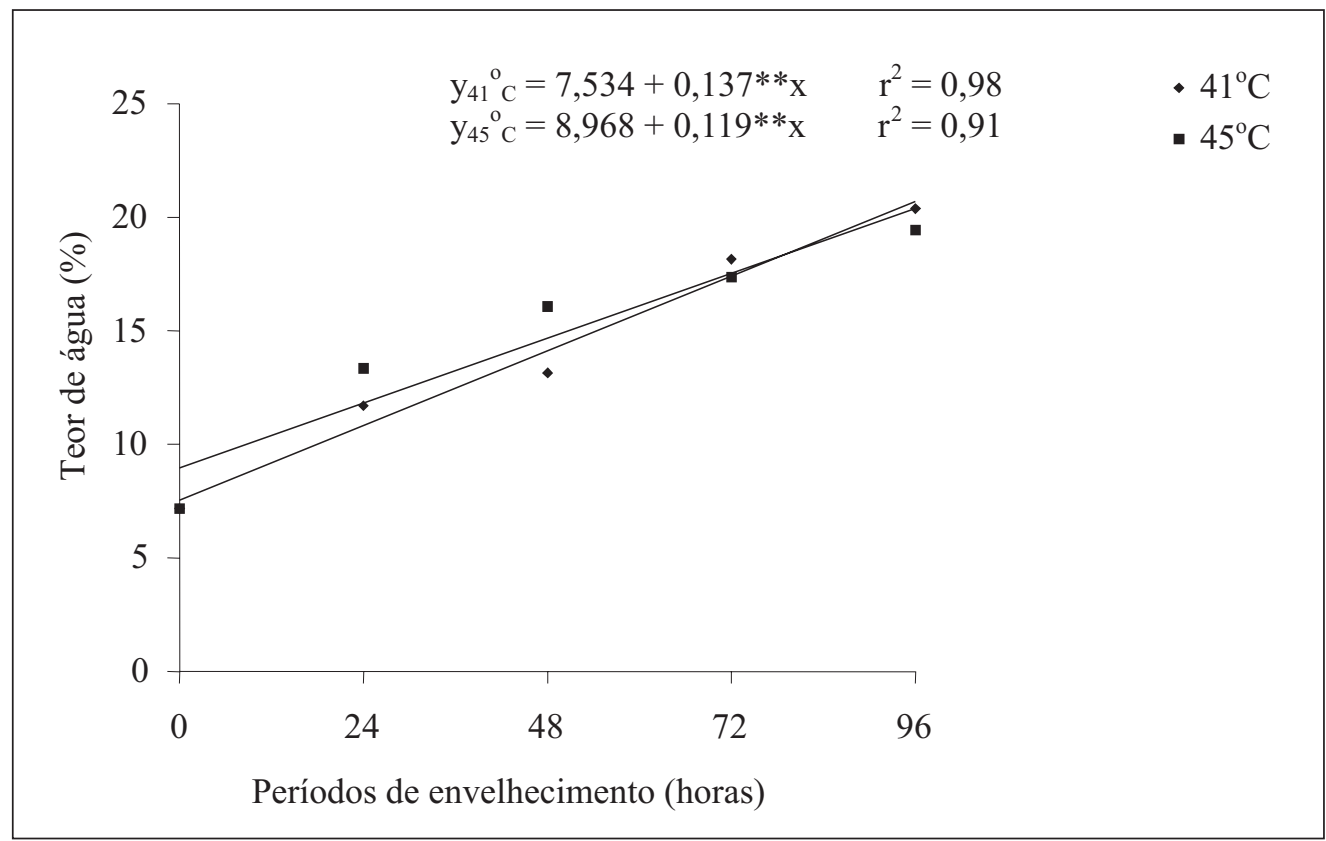

Figura 1. Teor de água de sementes de Erythrina velutina, antes e após o envelhecimento acelerado.

Quando se utilizou a temperatura de $45^{\circ} \mathrm{C}$, houve redução drástica nos valores de germinação após 24 horas, acentuando-se com o aumento do período de exposição ao envelhecimento, especificamente as 72 e 96 horas. Provavelmente, esta redução esteja associada ao processo de deterioração das sementes, quando submetidas às condições de altas temperaturas e alta umidade das sementes (Figuras 1 e 2).

De acordo com Tomes, Tekrony e Egli (1988), a elevação da temperatura no teste de envelhecimento promove efeitos mais drásticos na germinação do que o prolongamento do período de exposição ao envelhecimento. Resultados semelhantes foram observados por Borges, Castro e Borges (1990) com sementes de Cedrela fissilis, Santos et al. (2002) com sementes de milho doce, por Dutra e Vieira (2004), com sementes de milho, por Ramos et al. (2004) com sementes de rúcula por Maia, Lopes e Teixeira (2007) com sementes de trigo.

Oenvelhecimentodesementesocasionaalterações metabólicas durante o processo germinativo, incluindo metabolismo respiratório e funcionamento das membranas (BASAJAVARAJAPPA; SHETY; PRAKASH, 1991), síntese de proteínas, ácidos nucléicos e metabolismo do DNA (VÁZQUEZ; MONTIEL; VÁZQUEZ-RAMOS, 1991). O envelhecimento das sementes ocasiona atraso no processo germinativo, menor crescimento do embrião e suscetibilidade a estresses ambientais, levando eventualmente a perda da viabilidade.

À medida que as sementes foram envelhecidas houve uma redução no seu vigor. O teste de condutividade elétrica (Figura 3) detectou um aumento significativo na quantidade de lixiviados, tanto para as sementes submetidas ao envelhecimento nas temperaturas ensaiadas, sendo mais significativo quando as sementes foram submetidas à $45^{\circ} \mathrm{C}$. Com a desestruturação do sistema de membranas das organelas celulares, evidenciado pelo aumento progressivo na quantidade de lixiviados, as sementes tornam-se mais susceptíveis aos efeitos deletérios do $\mathrm{O}_{2}$, que promove a oxidação dos compostos e, também à ação de enzimas, que segundo Bewley e Black (1994), fazem com que as reservas sejam consumidas mais rapidamente. A redução gradativa da viabilidade e do vigor das sementes, 
promovida pelas condições estressantes durante o envelhecimento acelerado, pode ser observada pelas características avaliadas. Isto pode se dar a um maior consumo das reservas, decorrente da acelerada atividade metabólica nestas condições.

Como se verifica nesta pesquisa, a perda da viabilidade das sementes é resultante de eventos metabólicos importantes, sendo a deterioração manifestada por vários meios, os quais podem impedir a germinação (DESAI; KOTECHA; SALUNKE, 1997). Quando colocadas em condições favoráveis para germinação, as sementes envelhecidas apresentam menor atividade das enzimas hidrolíticas, as quais são responsáveis pela mobilização das reservas para o crescimento do embrião, do que as sementes não envelhecidas (FERREIRA et al., 2004).

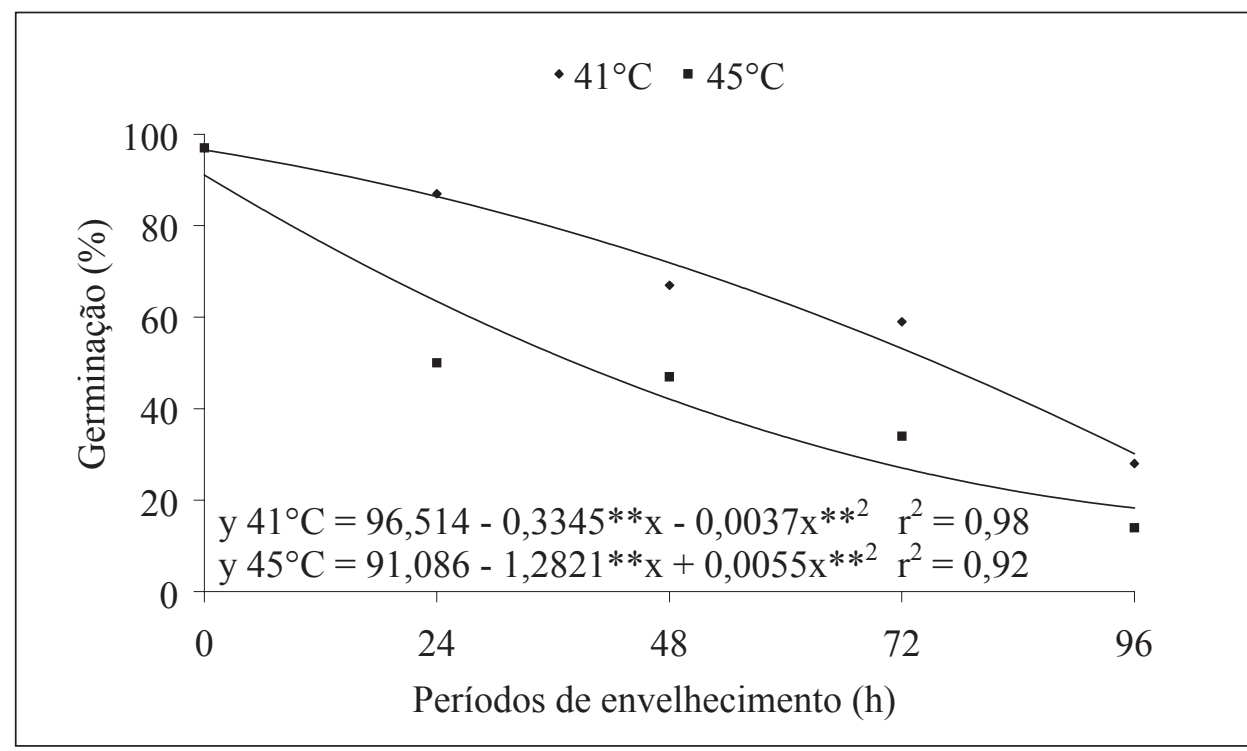

Figura 2. Germinação de sementes de Erythrina velutina antes e após o envelhecimento acelerado.

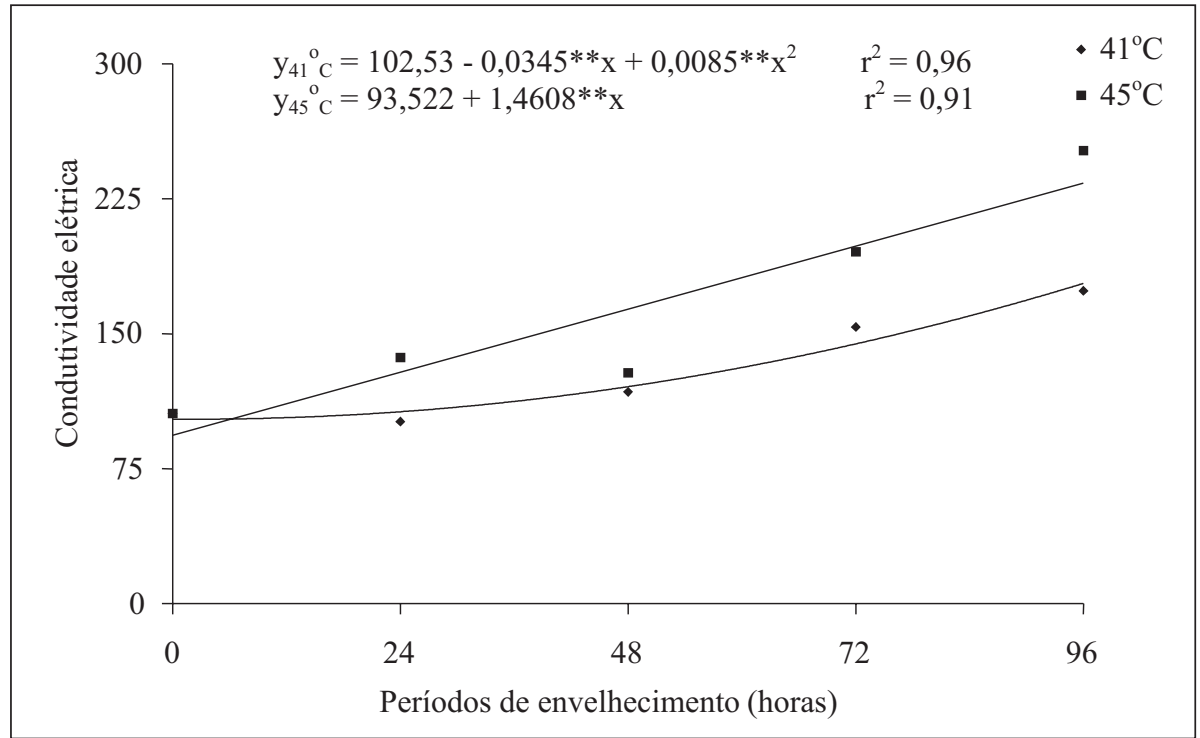

Figura 3. Condutividade elétrica da solução de embebição de sementes de Erythrina velutina antes e após o envelhecimento acelerado. 
Resultados semelhantes aos encontrados neste trabalho foram observados por Ferreira et al. (2004), com sementes de Copaifera langsdorffii. Borges, Castro e Borges (1992) e Fanti (1996) verificaram que sementes de Piptadenia communis e de Adenatnhera pavonina, respectivamente, reduziram significativamente a sua viabilidade e vigor quando submetidas ao envelhecimento acelerado, em condições de $45^{\circ} \mathrm{C}$ e $100 \%$ de umidade relativa, em relação ao controle. Perez e Nassif (1998) constataram que o mesmo processo ocorreu com sementes de Prosopis juliflora. Os autores consideraram que, quanto maior o tempo de envelhecimento menor será a viabilidade e o vigor de sementes das espécies estudadas.

\section{Conclusões}

$\mathrm{O}$ envelhecimento acelerado, em ambas as temperaturas $\left(41 \mathrm{e} 45^{\circ} \mathrm{C}\right)$, a partir de 24 horas afetou a qualidade fisiológica de sementes de mulungu (Erythrina velutina Will.), promovendo redução da viabilidade e do vigor.

As combinações $41^{\circ} \mathrm{C} / 72$ horas e $45^{\circ} \mathrm{C} / 24$ horas são adequadas para avaliação do vigor de sementes dessa espécie.

$\mathrm{O}$ vigor foi bastante afetado durante $\mathrm{O}$ envelhecimento, constatado pelo aumento na quantidade de lixiviados, observado no teste de condutividade elétrica.

\section{Referências}

ASSOCIATION OF OFFICIAL SEED ANALYSTS - AOSA. Seed vigortesting handbook. East Lansing: AOSA, 1983. (Contribution, 32).

BAGGIO, L.; LIMA, C. B.; SATO, O.; BUENO, J. T.; KOSTETZER, K.; LEITE, L. L.; BERTHI, D.; SILVA, M. Influência do número de horas de envelhecimento acelerado sobre as sementes de Nepeta cataria e Oreganum vulgare. Informativo ABRATES, Curitiba, v. 13, n. 3, p. 416, 2003.

BASAJAVARAJAPPA, B. S.; SHETY, S. H.; PRAKASH, H. S. Membrane deterioration and other biochemical changes, associated with accelerated aging of maize seeds. Seeds Sciece and Technology, Zurich, v. 2, n. 2, p. 279-286, 1991.

BEWLEY, J. D.; BLACK, M. Seeds: physiology of development and germination. 2. ed. New York: Plenum Press, 1994.

BORGES, E. E. L.; CASTRO, J. L. D.; BORGES, R. C. G. Alterações fisiológicas em sementes de jacaré (Piptadenia communis) submetidas ao envelhecimento precoce. Revista Brasileira de Sementes, Brasília, v. 14, n. 1, p. 9-12, 1992.

Avaliação fisiológica de sementes de cedro submetidas ao envelhecimento precoce. Revista Brasileira de Sementes, v. 12, n. 1, p. 56-62, 1990.

Avaliação fisiológica de sementes de cedro submetidas ao envelhecimento precoce. In: SIMPÓSIO BRASILEIRO DE TECNOLOGIA DE SEMENTES FLORESTAIS, 2., 1989, São Paulo. Anais... São Paulo: Instituto Florestal de São Paulo, 1991. p. 28.

BRASIL. Ministério da Agricultura e Reforma Agrária. Regras para análise de sementes. Brasília: SNDA/ DNDV/CLAV, 1992.

CARVALHO, N. M.; NAKAGAWA, J. Sementes: ciência, tecnologia e produção. 4. ed. Jaboticabal: Funep, 2000.

DELOUCHE, J. C.; BASKIN, C. C. Accelerated aging techniques for predicting the relative storability of seed lots. Seed Science and Technology, Zurich, v. 1, n. 2, p. 427-452, 1973.

DESAI, B. B.; KOTECHA, P. M.; SALUNKE, D. K. Seeds handbook: biology, production, processing and storage. New York: Marcel Dekker, 1997.

DUTRA, A. S.; VIEIRA, R. D. Envelhecimento acelerado como teste de vigor para sementes de milho e soja. Ciência Rural, Santa Maria, v. 34, n. 3, p. 715-721, 2004.

FANTI, S. C. Comportamento germinativo sob condições de estresse e influência do sombreamento artificial e adubação química na produção de mudas de Adenanthera pavonina L. 1996. Dissertação (Mestrado em Ecologia e Recursos Naturais) - Universidade Federal de São Carlos, São Carlos.

FERREIRA, R. A.; OLIVEIRA, L. M.; CARVALHO, D.; OLIVEIRA, A. F.; GEMAQUE, R. C. R. Qualidade fisiológica de sementes de Copaifera langsdorffii Desf. (Leguminosae Caesalpinioideae) envelhecidas artificialmente. Revista Ciência Agronômica, Fortaleza, v. 35, n. 1, p. 82-86, 2004. 
GARCIA, L. C.; NOGUEIRA, A. C.; ABREU, D. C. A. Influência do envelhecimento acelerado no vigor de sementes de Anadenanthera colubrina (Vellozo) Brenan - Mimosaceae. Ciência Florestal, Santa Maria, v. 14, n. 1, p. 85-90, 2004.

KUKIHARA, D. L.; IMAÑA-ENCINAS, J.; PAULA, J. E. Levantamento da arborização do campus da universidade de Brasília. Cerne, Lavras, v. 11, n. 2, p. 127-136, 2005.

LIMA, C. B.; ATHANÁZIO, J. C.; BELLETTINI, N. M. T. Germinação e vigor de sementes de alfavaca-cravo (Ocimum gratissimum L.) submetidas ao envelhecimento acelerado. Semina: Ciências Agrárias, Londrina, v. 27, n. 2, p. 159-170, 2006.

LIRA, R. S.; DANTAS, I. C.; CAVALCANTI, M. L. F.; BARROS, M. J. B.; LIRA, V. M.; CARNEIRO, P. T. Diagnóstico paisagístico do Parque da Criança em Campina Grande, PB. Revista de Biologia e Ciências da Terra, Campina Grande, v. 4, n. 1, p. 1-23, 2004.

LORENZI, H. Árvores brasileiras: manual de identificação e cultivo de plantas arbóreas nativas do Brasil. Nova Odessa: Plantarium, 1992.

MAIA, A. R.; LOPES, J. C.; TEIXEIRA, C. O. Efeito do envelhecimento acelerado na avaliação da qualidade fisiológica de sementes de trigo. Ciência Agrotécnica, Lavras, v. 31, n. 3, p. 678-684, 2007.

MARCOS FILHO, J. Testes de vigor: importância e utilização. In: KRZYZANOWSKI, F. C.; VIEIRA, R.D.; FRANÇA NETO, J. B. (Ed.). Vigor de sementes: conceitos e testes. Londrina: ABRATES, 1999a. p. 1-21.

Teste de envelhecimento acelerado. In: KRZYZANOWSKI, F. C.; VIEIRA, R. D.; FRANÇA NETO, J. B. (Ed.). Vigor de sementes: conceitos e testes. Londrina: ABRATES, 1999b. p. 1-24.

MENEZES, J. E.; NASCIMENTO, W. M. Teste de envelhecimento precoce em sementes de ervilha (Pisium sativum L.). Horticultura Brasileira, Brasília, v. 6, n. 1, p. 63, 1988. Resumos.

NAKAGAWA, J. Testes de vigor baseados no desempenho das plântulas. In: KRZYZANOSKI, F. C.;
VIEIRA, R. D.; FRANÇA NETO, J. B. (Ed.). Vigor de sementes: conceitos e testes. Londrina: ABRATES, 1999. p. 2.1-2.24.

PEREZ, S. C. J. G. A.; NASSIF, S. M. L. Efeitos do envelhecimento precoce, polietilenoglicol e substratos na viabilidade e vigor de sementes de algarobeira. Pesquisa Agropecuária Brasileira, Brasília, v. 33, n. 12, p. $2055-$ 2064, 1998.

RAMOS, N. P.; FLOR, E. P. O.; MENDONÇA, E. A. F.; MINAMI, K. Envelhecimento acelerado em sementes de rúcula (Eruca sativa L.). Revista Brasileira de Sementes, Pelotas, v. 26, n. 1, p. 98-103, 2004.

RODO, A. B.; PANOBIANCO, M.; MARCOS FILHO, J. Metodologia alternativa do teste de envelhecimento acelerado para sementes de cenoura. Scientia Agricola, Piracicaba, v. 57, n. 2, p. 289-292, 2000.

SANTOS, P. M.; GONDIM, T. C. O.; ARAUJO, E. F.; DIAS, D. C. F. S. Avaliação da qualidade fisiológica de sementes de milho doce pelo teste de envelhecimento acelerado. Revista Brasileira de Sementes, Londrina, v. 24, n. 1, p. 91-96, 2002.

TOMES, L. J.; TEKRONY, D. M.; EGLI, D. B. Factors influencing the tray accelerated aging test for soybean seed. Journal of Seed Technology, East Lansing, v. 12, n. 1, p. 24-35, 1988.

TORRES, S. B. Teste de envelhecimento acelerado em sementes de erva-doce. Revista Brasileira de Sementes, Brasília, v. 26, n. 2, p. 20-24, 2004.

TORRES, S. B.; MARCOS FILHO, J. Teste de envelhecimento acelerado em sementes de maxixe (Cucumis anguria L.). Revista Brasileira de Sementes, Brasília, v. 23, n. 2, p. 108-112, 2001.

VÁZQUEZ, E.; MONTIEL, F.; VÁZQUEZ-RAMOS, J. $M$. DNA ligase activity in deteriorated maize axes during germination: a model relating defects in DNA metabolism in seeds to loss of germinability. Seed Science Research, Wallingford, v. 1, n. 2, p. 269-273, 1991.

VIEIRA, R. D.; KRZYZANOWSKI, F. C. Teste de condutividade elétrica. In: KRZYZANOWSKI, F.C.; VIEIRA, R. D.; FRANÇANETO, J. B. Vigor de sementes: conceitos e testes. Jaboticabal: FUNEP, 1999. p. 1-26. 